\title{
Эффекты Холла и Зеебека в тонких пленках висмута на подложке из слюды в диапазоне температур $77-300 \mathrm{~K}$
}

\author{
(C) В.А. Комаров, В.М. Грабов, А.В. Суслов, Н.С. Каблукова, М.В. Суслов
}

Российский государственный педагогический университет им. А.И. Герцена, 191186 Санкт-Петербург, Россия

E-mail: va-komar@yandex.ru

(Поступила в Редакцию 20 декабря 2018 г.

В окончательной редакции 24 декабря 2018 г.

Принята к публикации 28 декабря 2018 г.)

На основе экспериментальных результатов исследования эффектов Холла и Зеебека пленок висмута на подложке из слюды проведен анализ влияния толщины пленок и размеров блоков на величину коэффициентов Холла и Зеебека. Выявлено преимущественное уменьшение вклада электронов при уменьшении толщины пленок и преимущественное уменьшение вклада дырок при уменьшении размера блоков. В рамках классического размерного эффекта с учетом рассеяния на границах блоков и анизотропии свойств носителей заряда проведен расчет коэффициентов Холла и Зеебека. При расчете использовались значения компонент подвижностей электронов и дырок и их концентрация в монокристалле висмута, а также учитывалась кристаллографическая ориентация пленочного кристалла. Результаты расчетов хорошо совпадают с экспериментальными результатами. Сделан вывод о том, что величина и знак коэффициентов Холла и Зеебека в пленках висмута определяются конкурирующим влиянием классического размерного эффекта и рассеяния на границах блоков.

DOI: 10.21883/FTP.2019.05.47545.03

\section{1. Введение}

В работах по исследованию тонких пленок висмута и сплавов висмут-сурьма наиболее часто приводятся результаты измерения удельного сопротивления и магнетосопротивления. Результаты исследования эффектов Холла и Зеебека встречаются гораздо реже. Рядом авторов отмечается существенный разброс получаемых результатов, особенно при низкой температуре.

Особенностью эффектов Холла и Зеебека является то, что электронные и дырочные составляющие имеют разные знаки. Следствием этого является значительное изменение величины коэффициентов Холла и Зеебека при изменении соотношения вкладов электронов и дырок. Изменение соотношения вкладов электронов и дырок в ряде работ связывают с нарушением равенства концентраций электронов и дырок в пленках [1-3], с поверхностными состояниями в пленке [4]. Ряд авторов связывают большое отрицательное значение коэффициента Холла в пленке с большой анизотропией эффекта Холла в висмуте и связанный с этим вклад компоненты $R_{321}$ блоков [5].

В „Лаборатории физики полуметаллов и узкозонных полупроводников“" нашего университета уже много лет проводится исследование монокристаллов и тонких пленок висмута и сплавов висмут-сурьма [6]. Это позволило накопить большой объем экспериментальных результатов исследования эффектов Холла и Зеебека в пленках висмута и висмут-сурьма. Наличие экспериментальных результатов позволило провести анализ и выявить причину большого разброса значений коэффициентов Холла и Зеебека в пленках висмута и сплавов висмут-сурьма.

\section{2. Экспериментальные результаты и их анализ}

Для выявления факторов, влияющих на величину коэффициентов Холла и Зеебека, были использованы результаты исследования пленок висмута на подложке из слюды мусковит, полученные в нашей лаборатории. Пленки были получены методом термического напыления в вакууме $10^{-5}$ Торр. Напыление производилось при температуре подложки $350-470 \mathrm{~K}$ в зависимости от необходимой структуры пленки и подвергались отжигу при температуре 520 К. Монокристаллические пленки были получены методом зонной перекристаллизации пленок под покрытием [7].

Исследование структуры пленок показало, что они все имеют блочную структуру с кристаллографической ориентацией блоков, соответствующей направлению оси $C_{3}$ перпендикулярно к плоскости пленки. Пленки, полученные методом зонной перекристаллизации, представляли собой единый монокристалл с осью $C_{3}$, перпендикулярной плоскости пленки.

Определение размеров блоков в пленках висмута производилось методом атомно-силовой микроскопии (ACM) поверхности пленки после химического травления с использованием методов описанных в работе [8].

При анализе были использованы экспериментальные результаты для более сотни образцов пленок висмута на слюде, полученные на протяжении большого периода времени. По этой причине далее на рисунках, для примера, приводятся температурные зависимости для отдельных образцов, отражающие наиболее характерные тенденции изменения значения коэффициентов Холла и Зеебека. 
На рис. 1 приведены температурные зависимости коэффициента Холла для пленок висмута толщиной 0.8 мкм, которые имеют различный размер блоков. Коэффициент Холла пленок одинаковой толщины существенно зависит от размеров блоков в пленке. В крупноблочных пленках коэффициент Холла положителен и увеличивается при понижении температуры. В мелкоблочных пленках коэффициент Холла положителен при $300 \mathrm{~K}$, но при понижении температуры он изменяет знак на отрицательный и увеличивается по абсолютной величине. Температура смены знака коэффициента Холла зависит от размера блоков в пленке: чем меньше размер блоков, тем выше температура смены знака. При $77 \mathrm{~K}$ в зависимости от размеров блоков коэффициент Холла изменяет свое значение от $-0.8 \cdot 10^{-6} \mathrm{M}^{3} /$ Кл в мелкоблочных пленках до $0.6 \cdot 10^{-6} \mathrm{M}^{3} /$ Кл в пленках с размером блоков много больше толщины пленки. В монокристаллической пленке толщиной 0.8 мкм величина коэффициента Холла при $77 \mathrm{~K}$ (рис. 2) еще больше, чем в крупноблочной пленке, и равна $1.1 \cdot 10^{-6} \mathrm{M}^{3} /$ Кл. Из приведенных экспериментальных результатов можно утверждать, что уменьшение размеров блоков в пленках висмута приводит к преимушественному уменьшению вклада дырок по сравнению с вкладом электронов.

На рис. 2 приведены температурные зависимости коэффициента Холла для монокристаллических пленок висмута различной толщины. Анализ результатов для монокристаллических пленок позволяет исключить влияние размеров блоков на свойства пленок. Коэффициент Холла монокристаллических пленок всех исследованных толщин положителен во всем исследованном интервале температуры и возрастает с понижением температуры. Уменьшение толщины пленки приводит к

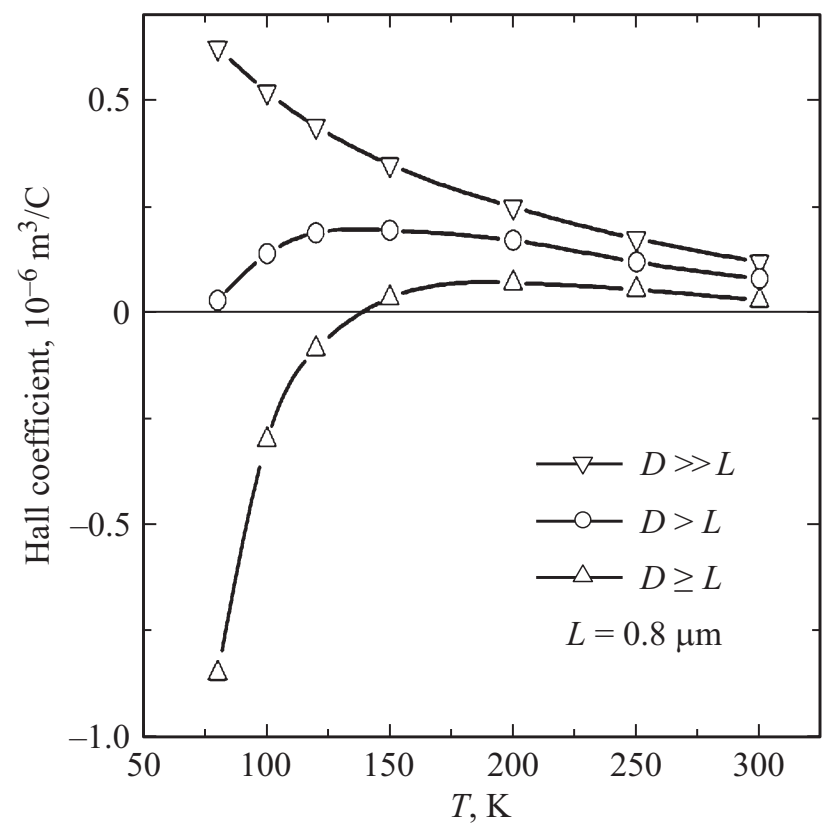

Рис. 1. Температурная зависимость коэффициента Холла пленок висмута толщиной 0.8 мкм, имеющих различный размер блоков $(D)$.

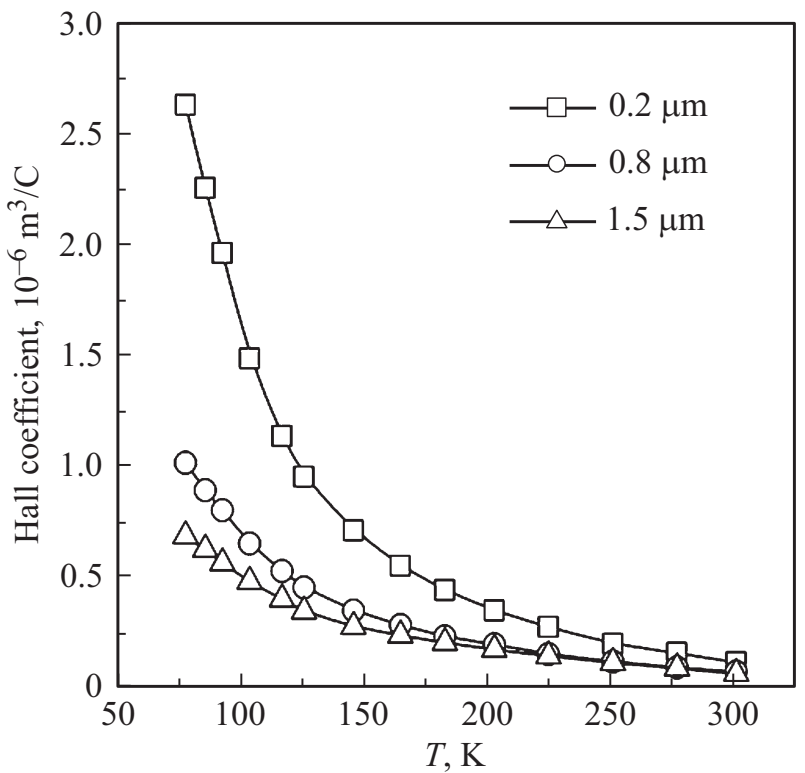

Рис. 2. Температурная зависимость коэффициента Холла монокристаллических пленок висмута различной толщины.

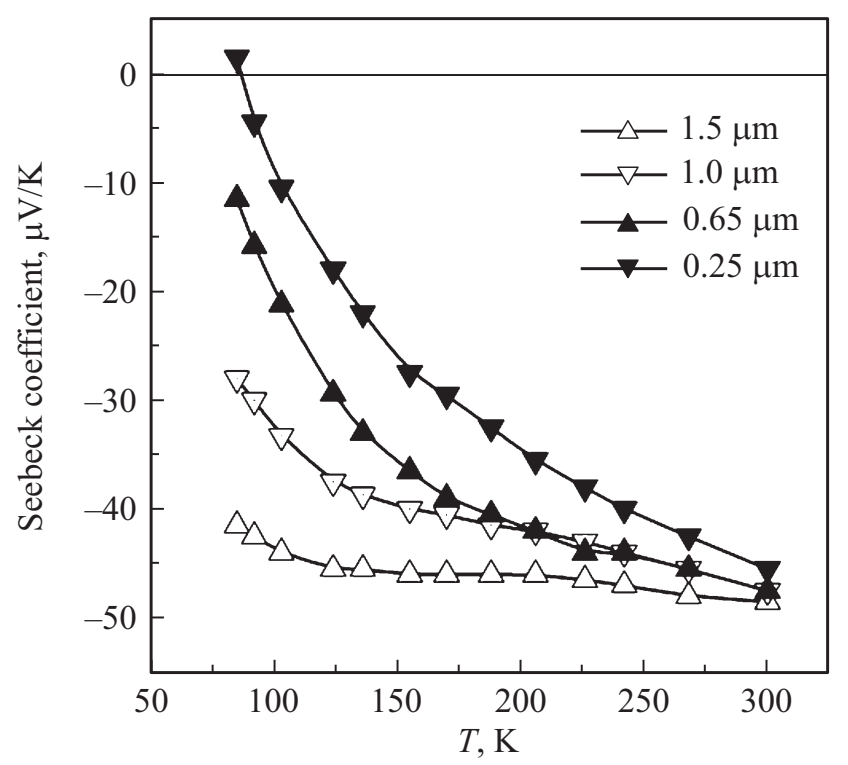

Рис. 3. Температурные зависимости коэффициента Зеебека монокристаллических пленок висмута различной толщины.

увеличению коэффициента Холла. На основании проведенного сравнения можно утверждать, что уменьшение толщины пленки приводит к преимущественному уменьшению вклада электронов по сравнению с вкладом дырок.

Аналогичное влияние оказывает толщина и размер блоков на эффект Зеебека в пленках висмута. На рис. 3 приведены температурные зависимости коэффициента Зеебека монокристаллических пленок висмута различной толщины на слюде. При $300 \mathrm{~K}$ значение коэффициента Зеебека всех пленок совпадает со значением 


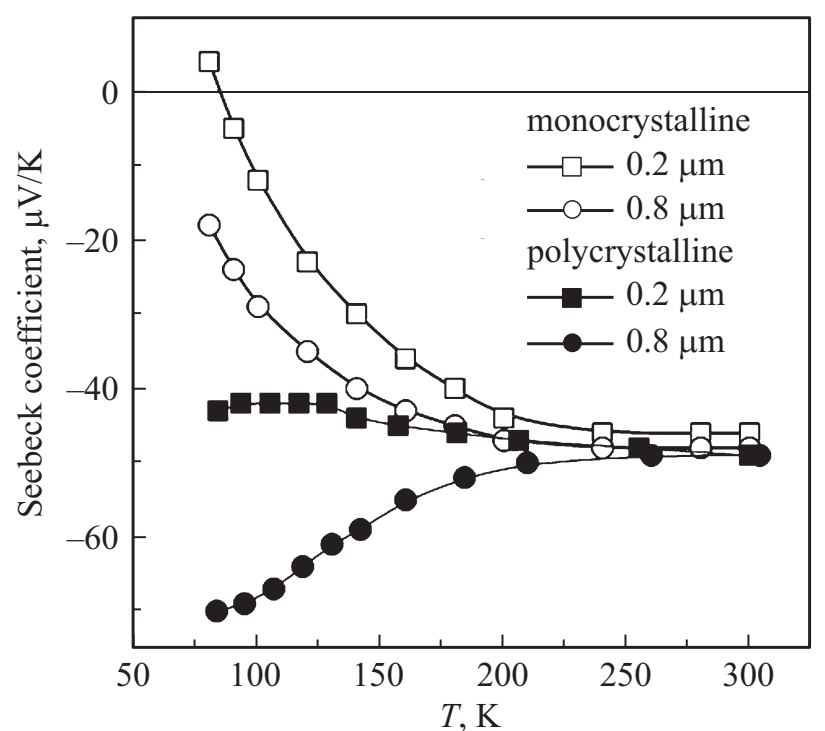

Рис. 4. Температурные зависимости коэффициента Зеебека монокристаллических и поликристаллических пленок висмута различной толщины.

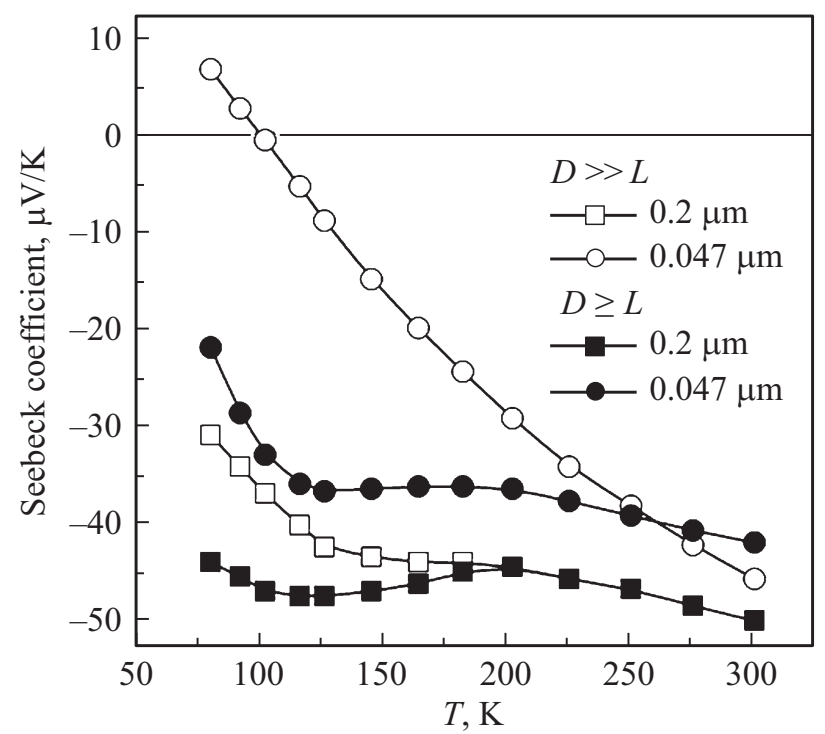

Рис. 5. Температурные зависимости коэффициента Зеебека пленок висмута толщиной 0.2 и 0.047 мкм с различным соотношением толщины и размера блоков.

коэффициента для монокристалла такой же ориентации. При уменьшении температуры значение коэффициента Зеебека в наиболее толстых пленках остается равным значению в монокристалле. Уменьшение толщины монокристаллической пленки приводит к уменьшению по абсолютной величине коэффициента Зеебека и даже к смене знака коэффициента на положительный при $\approx 100 \mathrm{~K}$ для наиболее тонкой пленки (0.25 мкм). Появление границ блоков в пленке приводит к увеличению по абсолютной величине отрицательного коэффициента Зеебека (рис. 4). Значение коэффициента Зеебека (поликристаллических) пленок висмута на слюде при $77 \mathrm{~K}$ может достигать -80 мкВ/К. Таким образом, по результатам наших исследований, коэффициент Зеебека пленок висмута на слюде при $77 \mathrm{~K}$ может иметь величину от -80 мкВ/К для мелкоблочных пленок толщиной $\approx 1$ мкм до $9 \mathrm{MKB} / \mathrm{K}$ для монокристаллической пленки толщиной 0.25 мкм.

Во всем многообразии возможных значений коэффициентов Холла и Зеебека пленок висмута на слюде можно выделить две закономерности. Уменьшение толщины пленки приводит к преимущественному уменьшению электронного вклада в эффекты Холла и Зеебека, а уменьшение размеров блоков приводит к преимущественному уменьшению дырочного вклада в эти эффекты. В блочных пленках висмута величины коэффициентов Холла и Зеебека определяются конкурирующим влиянием толщины пленки и размеров блоков в пленке. Хорошей иллюстрацией сказанного являются температурные зависимости коэффициента Зеебека на рис. 5. В крупноблочной пленке толщиной 47 нм при 100 К происходит смена знака коэффициента Зеебека на положительный. Подобная смена знака коэффициента Зеебека наблюдается в монокристаллической пленке (рис. 4), но значительно большей толщины (250 нм). Для мелкоблочной пленки толщиной 47 нм коэффициент Зеебека сохраняет отрицательное значение $(-20$ мкВ/K при $77 \mathrm{~K})$.

Аналогичные закономерности изменения коэффициентов Холла и Зеебека наблюдаются и в пленках $\mathrm{Bi}_{100-x} \mathrm{Sb}_{x}(0<x<15$ aт\%) на слюде. При этом необходимо учитывать изменение величины компонент $R_{123}$ и $\alpha_{11}$ монокристаллов соответствующего состава.

Рассмотренные примеры экспериментальных результатов позволяют высказать предположение, что изменение величин коэффициентов Холла и Зеебека связано с проявлением классического размерного эффекта и рассеянием на границах блоков. Такая взаимосвязь весьма вероятна, потому что анизотропия свойств электронов и дырок в висмуте различная: наименьшая подвижность дырок вдоль оси $C_{3}$, а электронов в перпендикулярном направлении. Для проверки высказанного предположения был проведен модельный расчет влияния классического размерного эффекта в сочетании с рассеянием на границах блоков на эффекты Холла и Зеебека на примере пленок висмута с использованием характеристик носителей заряда в монокристалле висмута.

\section{3. Модельный расчет и его результаты}

Основной моделью классического размерного эффекта в тонких металлических пленках является модель Фукса-Зондхаймера. Согласно этой модели, электропроводность тонких металлических пленок можно представить в виде

$$
\sigma_{L}=\sigma_{0}\left[1-\frac{3}{8}(1-p) \frac{l_{0}}{L}\right]
$$

при условии $l_{0} / L<l$. В этой формуле $\sigma_{0}, \sigma_{L}-$ электропроводности монокристалла и пленки, $l_{0}$ - длина 
Характеристики носителей заряда в монокристалле висмута ${ }^{a}$

\begin{tabular}{r|c|c|c|c|c|c|c|c|c|c}
\hline $\begin{array}{c}T, \\
\mathrm{~K}\end{array}$ & $\begin{array}{c}n=p, \\
10^{23} 1 / \mathrm{M}^{3}\end{array}$ & $\begin{array}{c}u_{1}^{-}, \\
\mathrm{m}^{2} / \mathrm{B} \cdot \mathrm{c}\end{array}$ & $\begin{array}{c}u_{2}^{-}, \\
\mathrm{m}^{2} / \mathrm{B} \cdot \mathrm{c}\end{array}$ & $\begin{array}{c}u_{3}^{-}, \\
\mathrm{M}^{2} / \mathrm{B} \cdot \mathrm{c}\end{array}$ & $\mu_{-}^{*}$ & $\begin{array}{c}u_{1}^{+}=u_{2}^{+}, \\
\mathrm{M}^{2} / \mathrm{B} \cdot \mathrm{c}\end{array}$ & $\begin{array}{c}u_{3}^{+}, \\
\mathrm{M}^{2} / \mathrm{B} \cdot \mathrm{c}\end{array}$ & $\mu_{+}^{*}$ & $\begin{array}{c}\alpha^{-}, \\
\mathrm{мКB} / \mathrm{K}\end{array}$ & $\begin{array}{c}\alpha^{+}, \\
\mathrm{M \kappa B} / \mathrm{K}\end{array}$ \\
\hline 80 & 4.61 & 67 & 0.84 & 36 & 4.55 & 11.2 & 1.02 & 2.7 & -105 & 150 \\
100 & 5.28 & 46.8 & 0.62 & 25 & 3.9 & 7.6 & 0.69 & 2.3 & -110 & 160 \\
150 & 7.6 & 21.0 & 0.30 & 10.7 & 3.1 & 4.2 & 0.38 & 1.7 & -115 & 170 \\
200 & 11.0 & 10.4 & 0.15 & 5.7 & 2.9 & 2.0 & 0.18 & 1.5 & -115 & 165 \\
250 & 15.8 & 6.0 & 0.08 & 3.0 & 3.3 & 1.1 & 0.1 & 1.85 & -110 & 160 \\
300 & 24.6 & 3.4 & 0.045 & 1.5 & 3.6 & 0.58 & 0.053 & 2.1 & -110 & 155
\end{tabular}

Примечание. ${ }^{a}$ Здесь $n, p-$ концентрации электронов и дырок; $u_{1}^{-}, u_{2}^{-}, u_{3}^{-}$- компоненты подвижности электронов в осях эллипсоида; $u_{1}^{+}, u_{2}^{+}$, $u_{3}^{+}$- компоненты подвижности дырок в осях дырочного эллипсоида; $\mu_{-}^{*}, \mu_{+}^{*}-$ приведенные энергии Ферми электронов и дырок; $\alpha^{-}, \alpha^{+}-$ парциальные вклады электронов и дырок в эффект Зеебека.

свободного пробега электронов в монокристалле, $L-$ толщина пленки, $p$ - коэффициент зеркальности. Другая формула (приближенная, но более удобная)

$$
\rho_{L}=\rho_{0}\left[1+\frac{3}{8}(1-p) \frac{l_{0}}{L}\right],
$$

где $\rho_{0}, \rho_{L}-$ удельное сопротивление монокристалла и пленки. В модели Фукса-Зондхаймера заложено условие одинаковости структуры объемного кристалла и тонкой пленки. Это означает, что если $\rho_{0}$ соответствует монокристаллу, то и пленка должна быть монокристаллической.

Реальные тонкие пленки, полученные конденсацией на подложку, представляют блочный кристалл с большим количеством межблочных границ. В работе [9] было получено уравнение, вытекающее из модели Фукса, позволяющее учитывать структуру тонких пленок. Позже в работе [10] было показано, что электрическое сопротивление в линейном приближении можно представить в виде

$$
\rho_{L}=\rho_{0}\left[1+\frac{3}{8} \frac{l_{0}}{D}\left(\frac{r}{1-r}\right)+\frac{3}{8}(1-p) \frac{l_{0}}{L}\right],
$$

где $D-$ средний размер блока в плоскости пленки, $r-$ коэффициент отражения электронов от границ блоков. Предположив, что концентрация носителей заряда в монокристалле и пленке одинаковая, формулу (3) можно переписать для подвижности носителей заряда в виде

$$
u_{L}=u_{0}\left[1+\frac{3}{8} \frac{l_{0}}{D}\left(\frac{r}{1-r}\right)+\frac{3}{8}(1-p) \frac{l_{0}}{L}\right]^{-1},
$$

где $u_{0}, u_{L}-$ подвижности носителей заряда в монокристалле и пленке.

Формулу (4) мы использовали в наших расчетах, но с учетом особенности свойств носителей заряда в висмуте и кристаллической структуры пленок висмута. Аналогичный подход использовался в работе [11] при анализе экспериментальных результатов исследования свойств пленок висмута, но без учета анизотропии свойств носителей заряда.
Висмут является многодолинным полуметаллом. Зонная структура висмута аппроксимируется одним дырочным эллипсоидом, вытянутым вдоль оси $C_{3}$, и тремя электронными эллипсоидами, вытянутыми в тригональной плоскости и развернутыми под углом $120^{\circ}$ друг относительно друга (угол наклона электронных эллипсоидов не учитывался). В осях эллипсоидов электроны характеризуются эффективными массами: $m_{1}^{*}=0.00606 m_{0}, m_{2}^{*}=1.27 m_{0}, m_{3}^{*}=0.0111 m_{0}$, а дырки: $m_{1}^{*}=m_{2}^{*}=0.064 m_{0}, m_{3}^{*}=0.703 m_{0}$.

Пленки висмута представляют собой блочный кристалл, в котором ось $C_{3}$ перпендикулярна плоскости пленки. Измеряемые на пленках висмута удельное сопротивление, коэффициент Холла в слабом магнитном поле и коэффициент Зеебека соответствуют компонентам $\rho_{11}, R_{123}$ и $\alpha_{11}$ соответствующих тензоров для монокристалла висмута и имеют вид

$$
\begin{gathered}
\frac{1}{\rho_{11}}=e p u_{1}^{+}+\frac{1}{2} e n\left(u_{1}^{-}+u_{2}^{-}\right), \\
R_{12,3}=\left[e p\left(u_{1}^{+}\right)^{2}-e n u_{1}^{-} u_{2}^{-}\right] /\left[e p u_{1}^{+}+\frac{1}{2} e n\left(u_{1}^{-}+u_{2}^{-}\right)\right]^{2}, \\
\alpha_{11}=\left[\alpha^{+} u_{1}^{+}+\alpha^{-} \frac{1}{2}\left(u_{1}^{-}+u_{2}^{-}\right)\right] /\left[u_{1}^{+}+\frac{1}{2}\left(u_{1}^{-}+u_{2}^{-}\right)\right],
\end{gathered}
$$

где $e$ - модуль заряда электрона, $n, p-$ концентрация электронов и дырок, $u_{1}^{-}, u_{2}^{-}, u_{1}^{+}$- компоненты подвижности электронов и дырок в осях соответствующих эллипсоидов, $\alpha^{-}$и $\alpha^{+}$- парциальные вклады электронов и дырок в эффект Зеебека.

Главной идеей наших расчетов является учет анизотропии свойств носителей заряда. Классический размерный эффект проявляется в электронной и дырочной подсистемах носителей заряда в соответствии с их свойствами. Значения параметров носителей заряда, использованные в расчетах, соответствуют параметрам электронов и дырок в монокристалле висмута и приведены в таблице. Численные значения использованных 

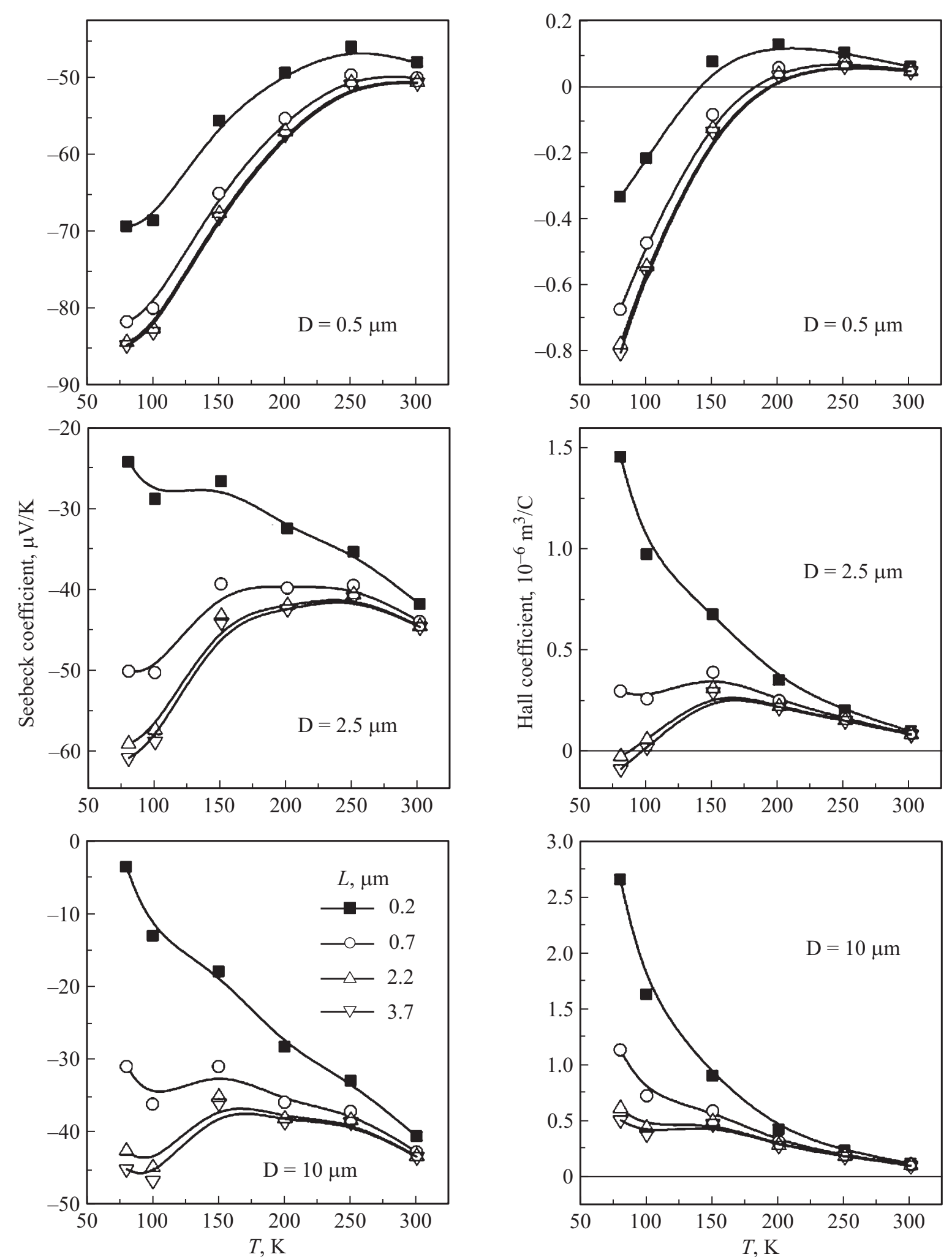

Рис. 6. Результаты расчетов температурных зависимостей коэффициента Холла и коэффициента Зеебека пленок висмута различной толщины $(L)$ и с различным размером блоков $(D)$.

параметров носителей заряда в монокристалле висмута были получены в нашей лаборатории [12] и хорошо согласуются с литературными данными.
С учетом кристаллографической ориентации пленочного кристалла ось $C_{3}$ перпендикулярна плоскости пленки), равенства концентрации носителей заряда в 
монокристалле и пленке, формула (4) для компоненты подвижности носителей заряда с индексом 1 была записана в виде

$$
\left(u_{1}\right)_{L}=\left(u_{1}\right)_{0}\left[1+\frac{3}{8} \frac{l_{1}}{D}\left(\frac{r}{1-r}\right)+\frac{3}{8}(1-p) \frac{l_{3}}{L}\right]^{-1},
$$

где $\left(u_{1}\right)_{0},\left(u_{1}\right)_{L}-$ компонента $u_{1}$ подвижности носителей заряда в осях эллипсоида в монокристалле и пленке, $l_{1}$ и $l_{3}$ компоненты длины свободного пробега носителей заряда в осях эллипсоида. Аналогично были опре елены все компоненты подвижности носителей заряда в пленке, необходимые для расчета коэффициента Холла и коэффициента Зеебека пленки. Расчет проведен при условии равенства концентрации электронов и дырок. Толщина пленки и размеры блоков в процессе расчетов варьировались.

Результаты расчетов коэффициентов Холла и Зеебека для некоторых значений среднего размера блоков $(D=0.5,2.5,10$ мкм $)$ и толщины пленки висмута $(L=0.2,0.7,2.2,3.7$ мкм) приведены на рис. 6. Характер изменения температурных зависимостей при варьировании толщины пленки и размеров блоков хорошо согласуются с экспериментальными зависимостями.

В процессе расчетов было проведено варьирование значения коэффициентов отражения электронов и дырок от границ блоков и коэффициента зеркальности. Наилучшее совпадение с экспериментальными результатами было получено при значениях коэффициента отражения для электронов равного, 0.1 , а для дырок - 0.8. Это указывает на более сильное рассеяние дырок на границах блоков, чем электронов. Коэффициент зеркальности для электронов и дырок принят равным 0.5.

Общие закономерности, которые прослеживаются в полученных результатах, совпадают с закономерностями, сформулированными на основе анализа экспериментальных результатов: уменьшение толщины пленки приводит к преимущественному уменьшению вклада электронов, а уменьшение размеров блоков приводит к преимущественному уменьшению вклада дырок в эффекты Холла и Зеебека. Результатом этого является возможность получения пленок висмута как с положительным коэффициентом Холла при $77 \mathrm{~K}$, так и с отрицательным в зависимости от соотношения толщины пленки и размеров блоков. Аналогичные возможности имеются и для изменения коэффициента Зеебека в пленках висмута при низкой температуре.

Некоторые различия экспериментальных и расчетных температурных зависимостей коэффициентов Холла и Зеебека, возможно, связаны с рядом упрощений при проведении расчетов. В расчетах предполагалось постоянство коэффициента зеркальности $(p)$ и коэффициента отражения от границ блоков $(r)$ во всем температурном диапазоне. Рассеяние на других видах дефектов вообще не учитывалось.

\section{4. Заключение}

На основании анализа экспериментальных результатов исследования эффектов Холла и Зеебека пленок висмута на слюде мусковит и проведенного модельного расчета в рамках классического размерного эффекта с учетом рассеяния на границах блоков для электронной и дырочной подсистемы носителей заряда можно утверждать, что конкурирующее влияние классического размерного эффекта и рассеяния на границах блоков обусловливает значительные отклонения как по величине так и по знаку коэффициентов Холла и Зеебека относительно их значения в монокристалле без нарушения равенства концентрации электронов и дырок.

Аналогичное влияние размерного эффекта и рассеяния на границах блоков прослеживается и в пленках висмута на других подложках [13], однако степень влияния толщины и размеров блоков на коэффициенты Холла и Зеебека могут отличаться от наблюдаемых в пленках висмута на слюде. Это связано с изменением параметров зонной структуры висмута в пленочном состоянии вследствие деформации пленочного кристалла подложкой [14].

Аналогичная связь коэффициентов Холла и Зеебека с толщиной пленки и размерами блоков наблюдается в пленках системы $\mathrm{Bi}_{100-x} \mathrm{Sb}_{x}\left(0<x<15 \mathrm{aT}_{0}\right)$ с учетом изменения величины компонент $R_{123}$ и $\alpha_{11}$ монокристаллов соответствующего состава.

Работа выполнена при финансовой поддержке Министерства образования и науки РФ (в рамках государственного задания, проект № 3.4856.2017/8.9).

\section{Список литературы}

[1] Mei Lu, R.J. Zieve, A. van Hulst, H.M. Jaeger, T.F. Rosenbaum, S. Radelaar. Phys. Rev. B, 53, 1609 (1996).

[2] C.A. Hoffmann, J.R. Meyer, F.J. Bartoli, A. Di Venere, X.J. Yi, C.L. Hou, H.C. Wang, J.B. Ketterson, G.K. Wong. Phys. Rev. B, 48, 11, 431(1993).

[3] R. Rosenbaum, J. Galibert. J. Phys.: Condens. Matter, 16, 5849 (2004).

[4] J. Buxo, M. Saleh, G. Sarrabayrouse, G. Dorville, J. Berty, M. Brieu. Rev. Phys. Appl., 15, 961 (1980).

[5] C. Butto, J. Berty. Thin Sol. Films, 131, 185 (1985).

[6] V.M. Grabov, V.A. Komarov, O.N. Uryupin. Int. Conf. on Thermoelectrics, ICT, Proceedings (1998) p. 241.

[7] В.М. Грабов, В.А. Комаров, Н.С. Каблукова, Е.В. Демидов, А.Н. Крушельницкий. Письма ЖТФ, 41 (1), 20 (2015).

[8] В.М. Грабов, Е.В. Демидов, В.А. Комаров. ФТТ, 50 (7), 1312 (2008).

[9] A.F. Mayadaset, M. Shatzkes. Phys. Rev. B, 1, 1382 (1970).

[10] F. Thiemeet, W. Kirstein. Thin Sol. Films, 30, 371 (1975).

[11] C. Pariset. Thin Sol. Films, 91, 301 (1982).

[12] Г.А. Иванов. ФТТ, 6, 938 (1964).

[13] М.В. Суслов, В.А. Комаров, М.В. Суслов. ФТП, 51 (7), 900 (2017).

[14] В.А. Комаров, А.В. Суслов, М.В. Суслов. ФТП, 51 (6), 736 (2017).

Редактор А.Н. Смирнов 


\section{Hall and Seebeck effects in bismuth \\ thin films on a mica substrate \\ in the temperature range $77-300 \mathrm{~K}$}

\section{V.A. Komarov, V.M. Grabov, A.V. Suslov, N.S. Kablukova, M.V. Suslov}

Herzen State Pedagogical University of Russia, 191186 St. Petersburg, Russia

Abstract We study the Hall and Seebeck coefficients of bismuth films on mica substrate in dependence on temperature and film thickness. The analysis of the experimental results reveals a preferential decrease of the contribution of electrons with decreasing film thickness and a decrease of the contribution of the holes with decreasing size of the film crystalline blocks. The Hall and Seebeck coefficients are calculated within the framework of the classical size effect taking into account the scattering at the boundaries of the blocks and the anisotropy of the charge carrier properties. In the calculations the values of mobility components of electrons and holes and their concentration for single crystal of bismuth were used, the crystallographic orientation of film crystal was taken into account. The results of the calculations are in good agreement with the experimental results. This allowed us to conclude that the magnitude and the sign of the Hall and Seebeck coefficients in bismuth films are determined by the competing influence of the classical size effect and scattering at the boundaries of the blocks. 